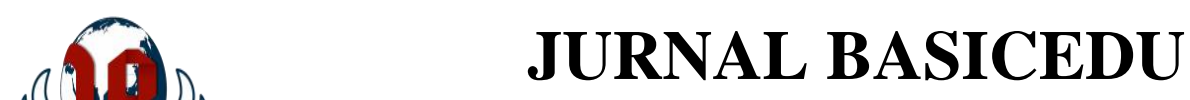

Volume 5 Nomor 4 Tahun 2021 Halaman 2363 - 2369

Research \& Learning in Elementary Education https://jbasic.org/index.php/basicedu

\title{
Penggunaan Model Assure untuk Meningkatkan Hasil Belajar Tematik Terpadu di Sekolah Dasar
}

\author{
Neneng Darlis ${ }^{1 凶}$, Mega Adyna Movitaria ${ }^{2}$ \\ Guru Sekolah Dasar Negeri 02 Simpang Kapuak, Indonesia ${ }^{1}$ \\ Institut Agama Islam Sumatera Barat, Indonesia ${ }^{2}$ \\ E-mail: darlisneneng85@gmail.com ${ }^{1}$, megaadyna.iaisumbar@gmail.com ${ }^{2}$
}

\begin{abstract}
Abstrak
Penelitian ini bertujuan meningkatkan hasil belajar tematik terpadu siswa Kelas V UPTD SDN 02 Simpang Kapuak Tahun Pelajaran 2019/2020 dengan menggunakan model ASSURE. Penelitian ini merupakan Penelitian Tindakan Kelas (PTK) yang dilaksanakan dalam 2 siklus dengan 2 kali pertemuan untuk tiap siklusnya. Subjek penelitian ini adalah peserta didik kelas V UPTD SDN 02 Simpang Kapuak Tahun Pelajaran 2019/2020 yang berjumlah 33 orang. Data dikumpulkan menggunakan lembar pengamatan keterlaksanaan desain pembelajaran, angket respon peserta didik, dan lembar pengamatan aktivitas siswa selama proses pembelajaran dan hasil belajar siswa. Data yang diperoleh diolah dan dianalisis secara deskriptif. Simpulan penelitian menunjukkan bahwa penggunaan model ASSURE dengan langkah-langkah yang benar dapat meningkatkan hasil belajar Tema 8 siswa Kelas V UPTD SDN 02 Simpang Kapuak Tahun Pelajaran 2019/2020.
\end{abstract}

Kata Kunci: model ASSURE, hasil belajar, pembelajaran tematik terpadu.

Abstract

This study aims to improve integrated thematic learning outcomes for students of Class V UPTD SDN 02 Simpang Kapuak for the 2019/2020 academic year by using the ASSURE model. This research is a Classroom Action Research (CAR) which was carried out in 2 cycles with 2 meetings for each cycle. The subjects of this study were students of class V UPTD SDN 02 Simpang Kapuak for the academic year 2019/2020, totaling 33 people. Data were collected using observation sheets on the implementation of learning designs, student response questionnaires, and observation sheets for student activities during the learning process and student learning outcomes. The data obtained were processed and analyzed descriptively. The conclusion of the study shows that the use of the ASSURE model with the correct steps can improve the learning outcomes of Theme 8 students of Class V UPTD SDN 02 Simpang Kapuak for the 2019/2020 academic year.

Keywords: ASSURE model, learning outcomes, integrated thematic learning.

Copyright (c) 2021 Neneng Darlis, Mega Adyna Movitaria

Corresponding author :

Email : darlisneneng85@gmail.com

DOI : https://doi.org/10.31004/basicedu.v5i4.1185

ISSN 2580-3735 (Media Cetak)

ISSN 2580-1147 (Media Online)

Jurnal Basicedu Vol 5 No 4 Tahun 2021

p-ISSN 2580-3735 e-ISSN 2580-1147 
2364 Penggunaan Model Assure untuk Meningkatkan Hasil Belajar Tematik Terpadu di Sekolah DasarNeneng Darlis, Mega Adyna Movitaria

DOI: https://doi.org/10.31004/basicedu.v5i4.1185

\section{PENDAHULUAN}

Pendidikan adalah hal penting yang tidak dapat dipisahkan dari kehidupan manusia. Dengan pendidikan ditentukan tingkat kemajuan suatu bangsa. Manusia dapat belajar kapan saja dan di mana saja tidak terbatas hanya pada bangku pendidikan formal. Belajar merupakan suatu perubahan dari tidak tahu menjadi tahu dan dari tidak bisa menjadi bisa sehingga proses belajar akan mengarah pada tujuan dari belajar itu sendiri. Usaha untuk mengajar dan mendidik dilakukan sejak awal kehidupan manusia dengan mengenalkan hal-hal sederhana melalui stimulus lingkungan, misalnya: bunyi/suara, rasa, warna, bentuk, dan sebagainya.

Pelaksanaan pendidikan di Indonesia diatur oleh Kementerian Pendidikan dan Kebudayaan Republik Indonesia melalui penetapan Standar Nasional Pendidikan (SNP). SNP dituangkan ke dalam 8 standar yang memuat kompetensi yang harus dikuasai siswa pada jenjang pendidikan tertentu. Pelaksanaan pendidikan diatur melalui penetapan kurikulum. Mulai tahun 2014 Pendidikan di Indonesia menggunakan Kurikulum 2013. Dalam pelaksanaan kurikulum 2013, proses pembelajaran dilaksanakan secara tematik terpadu. Pembelajaran tematik terpadu merupakan pembelajaran dengan mengintegrasikan beberapa muatan pelajaran ke dalam suatu tema. Pelaksanaan pembelajaran tematik terpadu berpusat pada siswa, tidak tampaknya pemisah antar mata pelajaran, konsep disajikan dari berbagai mata pelajaran, fleksibel, hasil pembelajaran berkembang sesuai dengan kebutuhan dan minat siswa. Kemendibud, (2013), menjelaskan bahwa konsep pendekatan ilmiah (scientific approach) dalam pembelajaran mencakup kegiatan mengamati, menanya, mencoba, mengolah, menyajikan, menyimpulkan, dan mencipta.

Pembelajaran tematik terpadu yang dilaksanakan di SD seharusnya mampu mengembangkan kemampuan berpikir siswa dalam melakukan suatu penemuan sehingga menghasilkan siswa yang mampu berpikir kreatif dan kritis terhadap permasalahan yang ada di sekitarnya. Harapan dari setiap guru dalam pembelajaran tematik terpadu adalah setiap siswa dapat mengusai konsep-konsep materi yang ada pada kurikulum. Dengan adanya pengusaan konsep-konsep materi maka pembelajaran tematik terpadu akan lebih bermakna bagi siswa. Sesuai dengan pendapat Hudojo yamg menyatakan bahwa pembelajaran merupakan suatu usaha mengarahkan siswa untuk terlibat aktif dalam belajarnya (Al-Tabany, 2014). Pembelajaran tematik terpadu diharapkan menggunakan pendekatan yang sesuai atau yang mudah diterima oleh siswa agar tercipta motivasi yang tinggi pada diri siswa dan diiringi dengan hasil belajar yang meningkat. Proses pembelajaran tidak dapat dipisahkan dari aktivitas yang dilakukan selama proses belajar. Demikian pentingnya proses belajar, sehingga jika seseorang ingin berhasil dalam pembelajaran, maka salah satu caranya adalah dengan mengefektifkan proses belajar dengan baik, agar hasil yang tercapai sesuai dengan apa yang diharapkan.

Berdasarkan hasil refleksi guru selama semester 1 Tahun Pelajaran 2019/2020, siswa merasa jenuh dan cenderung kurang fokus pada materi yang sedang dipelajari karena pembelajaran hanya didominasi oleh guru, yaitu guru berceramah kemudian mengerjakan soal tanpa adanya aktivitas belajar yang menyenangkan. Hal tersebut berdampak pada penguasaan materi oleh siswa yang dapat dilihat dari rendahnya hasil belajar siswa. Akhirnya siswa kelas V banyak mengalami kesulitan belajar. Hal ini dapat dilihat dari nilai Penilaian Harian (PH) yang dilaksanakan pada Tema 6 dari 33 siswa, diketahui ada 39,39\% siswa yang belum lulus KKM (75). Ini berarti baru 60,61\% siswa yang lulus KKM (75), dengan nilai tertinggi adalah 90 dan nilai terendah 40. Peneliti berharap tes hasil belajar siswa bisa mencapai bahkan melebihi target KKM yang telah ditetapkan.

Menurut Dudung, (2018) bahwa salah satu faktor yang mempengaruhi penyebab rendahnya hasil belajar siswa, adalah model pembelajaran yang digunakan guru masih kurang tepat dari harapan yang diinginkan sehingga motivasi belajar rendah yang berimplikasi pada hasil belajar siswa yang rendah. Kegiatan ceramah, selalu mendominasi pembelajaran. Kegiatan siswa terbatas pada mendengarkan ceramah guru, duduk dengan tenang serta diusahakan tetap diam saat belajar. Guru juga jarang memberi kesempatan dan stimulus pada siswa untuk bertanya. Hal ini terjadi karena guru banyak berpedoman pada LKS yang telah ada. Ketergantungan guru terhadap LKS meliputi materi yang diajarkan, tugas-tugas yang dikerjakan, maupun evaluasi yang dikerjakan 
2365 Penggunaan Model Assure untuk Meningkatkan Hasil Belajar Tematik Terpadu di Sekolah DasarNeneng Darlis, Mega Adyna Movitaria

DOI: https://doi.org/10.31004/basicedu.v5i4.1185

(Purnawati et al., 2019). Pendekatan pembelajaran yang digunakan oleh guru dalam proses pembelajaran masih berorientasi pada paradigma pendidikan yang lama. Guru masih mengajarkan materi sesuai dengan apa yang ada di dalam buku paket.

Sesuai dengan masalah yang dijumpai pada pembelajaran tematik terpadu siswa kelas V UPTD SDN 02 Simpang Kapuak tahun pelajaran 2019/2020 maka diperlukan model pembelajaran yang tepat. Prawiradilaga, (2018) mengemukakan bahwa desain Pembelajaran mengandung aspek bagaimana sebaiknya pembelajaran diselenggarakan/diciptakan melalui serangkaian prosedur serta penciptaan lingkungan belajar. Peneliti mencoba terobosan menggunakan model pembelajaran ASSURE. Bajracharya, (2019) menyatakan bahwa Model ASSURE adalah model desain pembelajaran yang menekankan pada faktor pemanfaatan media dan bahan ajar yang direncanakan dengan baik, sehingga membuat siswa belajar secara aktif sehingga menciptakan program pembelajaran yang efektif, efisien dan menarik serta menyenangkan bagi siswa. Model ASSURE ini tidak menyebutkan strategi pembelajaran secara eksplisit, jadi strategi pembelajarannya dikembangkan melalui pemilihan dan pemanfaatan metode, media, bahan ajar, serta peran serta siswa di kelas (Yaumi, 2018). Model ASSURE itu komponen proses pembelajaran lengkap, sederhana, dan relatif mudah untuk diterapkan. Karena sederhana, maka dapat dikembangkan sendiri oleh pengajar (Utami et al., 2018) .

Model ASSURE merupakan petunjuk prosedural dalam merencanakan dan menjalankan pembelajaran termasuk media dan teknologi pembelajaran yang akan dipakai. Model ASSURE merujuk pada analisis kebutuhan ideal untuk suatu kegiatan pembelajaran yang hasilnya diyakini dapat membantu guru mencapai tujuan pembelajaran secara efektif dan efisien. Karena seluruh aktifitas pembelajaran yang diterapkan merupakan hasil analisis yang mendalam yang dituangkan dalam suatu perencanaan yang resmi dan selanjutnya diaplikasikan dalam kegiatan pembelajaran (Nawawi, 2018).

Pengertian desain pembelajaran adalah proses sistemik dan reflektif menerjemahkan prinsip-prinsip pembelajaran dan pengajaran dalam rencana untuk bahan ajar, kegiatan, sumber daya informasi, dan evaluasi (Suharni, 2019). Dalam hal ini, Suharni, (2019) menegaskan bahwa desain pembelajaran adalah proses sistematis dan reflektif dalam menerjemahkan prinsip dan langkah pembelajaran dalam perencanaan bahan ajar, aktivitas, sumber, dan evaluasi pembelajaran.

Model ASSURE dikembangkan oleh Smaldino pada tahun 2005 (Kim \& Downey, 2016) . Huruf demi huruf dari katanya merupakan rincian langkah dalam membuat rancangan pembelajaran. Model ASSURE adalah suatu rencana yang digunakan untuk membantu guru mengorganisasikan prosedur pembelajaran, dan melakukan penilaian autentik (Handayani \& Marjono, 2018).

Menurut Kim \& Downey, (2016) bahwa Model ASSURE memiliki enam tahapan yang terdiri dari: (a) Menganalisis siswa (analyze learner), (b) merumuskan standar dan tujuan (state standard and objectives), (c) memilih strategi, teknologi, media dan materi ajar (select methods, media, and materials), (d) memanfaatkan teknologi, media dan materi ajar (utilize methods, media, and materials), (e) mengajak siswa untuk berpartisipasi (requires learner participation), (f) melakukan evaluasi dan revisi (evaluate and revise).

Berdasarkan uraian di atas, rumusan masalah yang muncul yaitu (1) bagaimanakah langkah-langkah penggunaan model ASSURE yang dapat meningkatkan hasil belajar tematik terpadu siswa kelas V UPTD SDN 02 Simpang Kapuak?, (2) apakah penggunaan model ASSURE dapat meningkatkan hasil belajar tematik terpadu siswa kelas V UPTD SDN 02 Simpang Kapuak.

Tujuan penelitian ini yaitu (1) untuk mendeskripsikan langkah-langkah penggunaan model ASSURE dalam meningkatkan hasil belajar tematik terpadu siswa Kelas V UPTD SDN 02 Simpang Kapuak (2) untuk meningkatkan hasil belajar tematik terpadu siswa Kelas V UPTD SDN 02 Simpang Kapuak.

\section{METODE}

Penelitian dilaksanakan di kelas V UPTD SDN 02 Simpang Kapuak. Jumlah subjek penelitian 33 siswa yang terdiri atas 18 siswa laki-laki dan 15 siswa perempuan. Waktu penelitian dilaksanakan mulai bulan Januari 
2020 sampai dengan bulan Juni 2020 pada semester dua tahun ajaran 2019/2020. Data dalam penelitian ini diperoleh melalui penggunaan instrumen tes dan non tes. Instrumen tes berupa lembar soal evaluasi hasil belajar siswa, sedangkan instrumen non tes terdiri dari lembar pengamatan keterlaksanaan desain pembelajaran, angket respon siswa, dan lembar pengamatan aktivitas siswa selama proses pembelajaran.

Dalam melakukan penelitian ini, peneliti berkolaborasi dengan 2 orang rekan sejawat yang bertindak sebagai observer. Data hasil penelitian berupa hasil observasi berupa lembar keterlaksanaan desain pembelajaran, angket respon siswa, dan lembar hasil pengamatan aktivitas siswa selama proses pembelajaran.

Analisis data dilakukan dengan analisis deskriptif komparatif untuk membandingkan data kuantitatif berupa hasil belajar siswa tiap siklus dan analisis kualitatif yang mengacu pada pendapat Miles dan Hiberman meliputi tiga langkah kegiatan meliputi reduksi dan penyajian data, serta penarikan kesimpulan, yang dilakukan selama dan setelah pengumpulan data selesai (Sugiyono, 2015). Keabsahan data diuji dengan menggunakan teknik triangulasi berupa triangulasi sumber dan triangulasi teknik.

Prosedur penelitian ini menggunakan metode penelitian tindakan kelas. Prosedur penelitian tindakan kelas mencakup perencanaan dan pelaksanaan tindakan, pengamatan, serta refleksi. Dalam penelitian tindakan kelas ini digunakan model penelitian yang dikembangkan oleh Arikunto, (2021) yang meliputi empat tahapan yang digunakan dan mencakup perencanaan, tindakan, observasi, dan refleksi. Pada pelaksanaannya, tahapan ini selalu berhubungan dan berkelanjutan dalam prosesnya, serta mengalami perbaikan sesuai dengan hasil observasi dan refleksi hingga memenuhi hasil atau tujuan yang diharapkan.

\section{HASIL DAN PEMBAHASAN}

Proses pembelajaran tematik terpadu dengan penggunaan model ASSURE oleh guru yaitu bahwa pelaksanaan guru dalam mengajar pada siklus I sudah menunjukan langkah-langkah pembelajaran dengan model ASSURE sesuai dengan pendapat Bajracharya, (2019) yaitu Analyze Learner Characteristic; State Objective; Select Methods, Media, and Materials; Utilize Media and Materials, Require Learner Participation dan Evaluate. Peningkatan hasil belajar tematik terpadu siswa Kelas V UPTD SDN 02 Simpang Kapuak dengan menggunakan model ASSURE dilaksanakan dengan dua siklus. Setiap siklus dilaksanakan sebanyak dua kali pertemuan, dengan alokasi waktu 2 jam pelajaran atau 2 × 35 menit.

Data rata-rata hasil observasi yang diperoleh dari dua orang observer terkait penggunaan desain pembelajaran model ASSURE pada pembelajaran tematik terpadu oleh guru pada siklus I sampai siklus II adalah sebagai berikut:

Tabel 1

Persentase Keterlaksanaan Model ASSURE pada Siklus I dan II Langkah Model ASSURE

\begin{tabular}{|c|c|c|c|c|c|c|c|}
\hline \multicolumn{6}{|c|}{ Langkah Model ASSURE } & \multirow{3}{*}{ Rata-rata } & \multirow{3}{*}{ Kategori } \\
\hline Sik & us I & Rata-rata & Sik & S II & Rata-rata & & \\
\hline P1 & P2 & Siklus I & P1 & P2 & Siklus II & & \\
\hline 76,68 & 82,82 & 79,75 & 88,48 & 96,36 & 92,42 & 86,09 & Sangat Baik \\
\hline
\end{tabular}

Berdasarkan tabel 1 dapat disimpulkan bahwa persentase keterlaksanaan model ASSURE siklus I mencapai 79,75\%, sedangkan pada siklus II mencapai 92,42\%. Pelaksanaan langkah-langkah pembelajaran model ASSURE yang belum berjalan dengan baik berdampak pada aktivitas belajar siswa. Adapun hasil observasi penggunaan model ASSURE terhadap aktivitas siswa pada siklus I sampai siklus II dapat dilihat pada tabel berikut:

Tabel 2

Persentase Aktivitas Siswa pada Siklus I dan II

\begin{tabular}{|c|c|c|c|c|c|c|c|}
\hline \multicolumn{6}{|c|}{ Langkah Model ASSURE } & \multirow{3}{*}{ Rata-rata } & \multirow{3}{*}{ Kategori } \\
\hline \multicolumn{2}{|c|}{ Siklus I } & \multirow{2}{*}{$\begin{array}{c}\text { Rata-rata } \\
\text { Siklus I }\end{array}$} & \multicolumn{2}{|c|}{ Siklus II } & \multirow{2}{*}{$\begin{array}{l}\text { Rata-rata } \\
\text { Siklus II }\end{array}$} & & \\
\hline P1 & $\mathbf{P 2}$ & & P1 & $\mathbf{P 2}$ & & & \\
\hline 66,67 & 72,73 & 69,7 & 84,85 & 90,91 & 87,88 & 78,79 & Baik \\
\hline
\end{tabular}


2367 Penggunaan Model Assure untuk Meningkatkan Hasil Belajar Tematik Terpadu di Sekolah DasarNeneng Darlis, Mega Adyna Movitaria

DOI: https://doi.org/10.31004/basicedu.v5i4.1185

Dari tabel 2 dapat disimpulkan bahwa persentase penggunaan model ASSURE terhadap siswa pada siklus I mencapai $69,7 \%$, sedangkan pada siklus II mencapai $87,88 \%$. Faktor yang menghambat jalannya kegiatan pembelajaran pada siswa adalah faktor kesiapan. Sesuai dengan pendapat Latiana et al., (2018) yang menjelaskan bahwa salah satu faktor intern yang mempengaruhi pelaksanaan kegiatan pembelajaran adalah faktor kesiapan. Kegiatan belajar siswa pada siklus II juga sudah berjalan dengan lebih baik, siswa tampak lebih fokus pada materi yang sedang dipelajari dengan memanfaatkan media yang ada dan siswa sudah sangat antusias dalam berpendapat di kelas. Hal tersebut senada dengan pendapat Nawawi, (2018) yang menjelaskan bahwa "Model ASSURE adalah model pembelajaran yang dikembangkan melalui pemilihan metode, media, dan peran serta siswa di kelas. Sedangkan perolehan rata-rata nilai hasil belajar siswa pada siklus I dan siklus II adalah sebagai beikut:

\section{Tabel 3}

Perolehan Hasil Belajar Tematik Terpadu

\begin{tabular}{lcccc}
\hline & \multicolumn{2}{c}{ Hasil Belajar Tematik Terpadu } \\
\hline \multirow{2}{*}{ Tindakan } & \multicolumn{2}{c}{ Tuntas } & \multicolumn{2}{c}{ Belum Tuntas } \\
\cline { 2 - 5 } & Frekuensi & \% & Frekuensi & \% \\
\hline Siklus I & 25 & 75,76 & 8 & 24,24 \\
\hline Siklus II & 31 & 93,94 & 2 & 6,06 \\
\hline
\end{tabular}

Berdasarkan tabel 3 menunjukkan bahwa hasil belajar tetatik terpadu siswa kelas V semakin meningkat. Pada siklus I ketuntasan hasil belajar siswa mencapai 75,76\% atau sebanyak 25 siswa. Pada siklus II meningkat menjadi 93,94\% atau sebanyak 31 siswa.

Keberhasilan penggunaan pembelajaran model ASSURE pada tematik terpadu dengan kategori sangat baik karena diawali beberapa tahap desain yang sangat kompleks. Secara teoretik, keberhasilan dalam penggunaan model desain pembelajaran ini sejalan dengan pandangan (Hosnan, 2014), yang menyatakan bahwa jaring tema sebaiknya disesuaikan dengan kebutuhan peserta didik agar pembelajaran bermakna bagi mereka.

Temuan bahwa pengembangan desain pembelajaran dengan model ASSURE sejalan dengan penelitian Muhammad Nawawi \& Ana Christanti, (2020) yang meneliti tentang Mendesain Pembelajaran Efektif Berdasarkan Model ASSURE, menunjukan bahwa model mampu menggunakan teknologi terbaru dan media berbasis teknologi ke dalam pembelajaran secara tepat dan efektif. Demikian juga penelitian Kadir, (2018) yang meneliti tentang Peningkatan Kreatifitas Guru dalam Mengajar Melalui pelatihan Model ASSURE dengan Pendekatan Saintifik pada MGMP Pendidikan Agama Islam di Sekolah Menengah Atas Kabupaten Indragiri Hulu Tahun 2017, hasilnya menunjukkan bahwa terjadi peningkatan kemampuan guru setelah diberi pelatihan model ASSURE dari rata-rata kemampuan 44,44\% naik menjadi 100\%. Simpulannya, hasil tersebut membuktikan bahwa desain pembelajaran model ASSURE telah valid dan layak digunakan dalam pembelajaran.

Dalam penelitian ini hasil belajar dapat ditingkatkan ketika guru menggunakan model ASSURE yang bertujuan agar siswa terlibat aktif dan tertarik dalam mengikuti pembelajaran. Hal ini didukung dengan pendapat ahli Noviandi et al., (2020) bahwa model ASSURE melibatkan partisipasi siswa dalam pembelajaran. Selain itu langkah ASSURE yang memudahkan guru dalam menciptakan suatu proses pembelajaran yang menyenangkan yaitu guru menganalisis karakteristik siswa, menetapkan tujuan pembelajaran, memilih metode, media, dan bahan ajar, memanfaatkan media dan bahan, mendorong partisipasi siswa, dan terakhir evaluasi dan revisi Pribadi, (2017). Faiza, (2019) juga berpendapat bahwa The ASSURE model merupakan panduan prosedural untuk merencanakan dan menyampaikan pelajaran yang menyertakan media. Berdasarkan hasil analisis data ditemukan adanya peningkatan hasil belajar siswa. Hal ini menandakan bahwa penggunaan model ASSURE dapat meningkatkan hasil belajar dalam pembelajaran tematik terpadu sehingga menjadikan pembelajaran menjadi lebih bermakna. 
2368 Penggunaan Model Assure untuk Meningkatkan Hasil Belajar Tematik Terpadu di Sekolah DasarNeneng Darlis, Mega Adyna Movitaria

DOI: https://doi.org/10.31004/basicedu.v5i4.1185

\section{KESIMPULAN}

Berdasarkan hasil analisis pelaksanaan penelitian, hasil penelitian dan pembahasan, maka dapat disimpulkan bahwa penelitian penggunaan model ASSURE yang dilaksanakan dengan langkah-langkah yang benar dapat meningkatkan pembelajaran tematik terpadu pada siswa kelas V UPTD SDN 02 Simpang Kapuak Tahun Pelajaran 2019/2020.

Selanjutnya, dari hasil penelitian di atas, peneliti memberikan saran kepada guru untuk menggunakan model ASSURE pada pembelajaran tematik terpadu di kelas $\mathrm{V}$ dan dikembangkan pada tingkatan kelas yang lain karena penggunaan model ASSURE dengan langkah-langkah yang benar terbukti dapat meningkatkan pembelajaran siswa. Dalam pelaksanaan pembelajaran dengan menggunakan model ASSURE guru juga disarankan untuk memperhatikan tiap langkah pembelajaran model ASSURE dan memperhatikan aktivitas belajar siswa sehingga suasana kelas menjadi kondusif.

Selanjutnya peneliti juga memberikan saran kepada sekolah hendaknya meningkatkan jumlah media pelajaran yang tersedia sehingga memudahkan guru dalam memberikan pengalaman belajar pada siswa dengan menggunakan model ASSURE. Sedangkan kepada siswa, peneliti memberikan saran agar lebih fokus dalam mengikuti kegiatan pembelajaran dengan menggunakan model ASSURE. Selain itu aktivitas belajar siswa juga diharapkan lebih dikendalikan agar pelaksanaan kegiatan pembelajaran dapat berjalan dengan lebih kondusif.

\section{UCAPAN TERIMA KASIH}

Penulis mengucapkan banyak-banyak teriakasih kepada Allah SWT Yang sudah memberikan penulis Kesehatan dan kelancaraan. Dan penulis mengucapkan terimakasih kepad pihak-pihak yang telah membantu untuk melakukan penelitian ini.

\section{DAFTAR PUSTAKA}

Al-Tabany, T. I. B. (2014). Mendesain model pembelajaran inovatif, progresif, dan kontekstual. In Prenadamedia Group.

Arikunto, S. (2021). Penelitian tindakan kelas: Edisi revisi. Bumi Aksara.

Bajracharya, J. R. (2019). Instructional Design and Models: ASSURE and Kemp. Journal of Education and Research. https://doi.org/10.3126/jer.v9i2.30459

Dudung, A. (2018). Kompetensi Profesional Guru. JKKP (Jurnal Kesejahteraan Keluarga Dan Pendidikan). https://doi.org/10.21009/jkkp.051.02

Faiza, P. N. (2019). Pengembangan Media E-Learning Webquest Berbasis Problem Solving Menggunakan Model ASSURE.

Handayani, S., \& Marjono, M. (2018). The Development of Adobe Flash CC (Creative Cloud) Based Interactive Multimedia Module in History Subjects in Grade XI of Senior High School with ASSURE Model. Historica Journal, 2(2).

Hosnan. (2014). Pendekatan Saintifik dan Kontekstual dalam Pembelajaran Abad 21. Ghalia Indonesia.

Kadir, A. (2018). Peningkatan Kreativitas Guru Dalam Mengajar Melalui Pelatihan Model Assure Dengan Pendekatan Scientific Pada Mgmp Pendidikan Agama Islam Di Sekolah Menengah Atas Kabupaten Indragiri Hulu Tahun 2017. Akademika.

Kemendikbud. (2013). Permendikbud No.65 tentang Standar Proses Pendidikan Dasar dan Menengah. Kementerian Pendidikan dan Kebudayaan.

Kim, D., \& Downey, S. (2016). Examining the Use of the ASSURE Model by K-12 Teachers. Computers in the Schools, 33(3), 153-168.

Latiana, L., Samsudi, S., Sugiyo, S., \& Slameto, S. (2018). Developing Collaboration-Based Supervision Model 
2369 Penggunaan Model Assure untuk Meningkatkan Hasil Belajar Tematik Terpadu di Sekolah DasarNeneng Darlis, Mega Adyna Movitaria

DOI: https://doi.org/10.31004/basicedu.v5i4.1185

to Enhance the Professionalism of Early Childhood Education Teachers. The Journal of Educational Development, 6(1), 132-143.

Muhammad Nawawi, \& Ana Christanti. (2020). Promotıng Mult1literacy Framework - Based Lesson Plan for English Language Teaching In Senır High School. Education and Human Development Journal. https://doi.org/10.33086/ehdj.v5i2.1549

Nawawi, N. (2018). Mendesain Pembelajaran Efektif Berdasarkan Model'Assure'. Prosiding Konferensi Nasional Pengabdian Kepada Masyarakat Dan Corporate Social Responsibility (PKM-CSR), 1, 13021307.

Noviandi, H., Neviyarni, S., \& Farida, F. (2020). Pengembangan Desain Pembelajaran Model Assure Menggunakan VAK di Sekolah Dasar. Jurnal Basicedu, 4(4), 977-984.

Prawiradilaga, D. S. (2018). Kajian Learning Content Management Systems (Lcms) Dalam Kerangka Disain Pembelajaran. Jurnal Teknodik, 13(1), 35-51.

Pribadi, R. B. A. (2017). Media dan Teknologi dalam Pembelajaran. Jakarta: Kencana.

Purnawati, S., Fauzan, A., \& Rasidin, S. (2019). Contextual Learning Styles-Based Approach to Improve Mathematics Learning Outcomes In Primary School. https://doi.org/10.2991/icoie-18.2019.18

Sugiyono. (2015). Metode Penelitian Pendidikan Pendekatan Kuantitatif, Kualitatif, dan R \& D. Alfabeta.

Suharni, L. T. (2019). Pengembangan Desain Pembelajaran dengan Model Assure pada Pembelajaran Tematik Terpadu di Sekolah Dasar. Jurnal Basicedu, 3(3), 978-982.

Utami, D. W., Anwar, M., \& Hermawan, H. (2018). Pengaruh Penggunaan Model Pembelajaran Assure terhadap Peningkatan Prestasi Belajar IPA Anak Tunalaras Kelas IV di SLB E Bhina Putera Surakarta Tahun Ajaran 2017/2018. JPI (Jurnal Pendidikan Inklusi). https://doi.org/10.26740/inklusi.v2n1.p5-14

Yaumi, M. (2018). Penerapan Model Assure dalam Pengembangan Media dan Teknologi Pembelajaran PAI. 